\title{
Ureteric Suture Urolithiasis Following Open Emergency Ureteric Repair
}

\author{
Piyush B. Sarmah Brian D. Kelly Raghuram Devarajan \\ Department of Urology, City Hospital, Birmingham, UK
}

\author{
Key Words \\ Ureter $\cdot$ Suture $\cdot$ Urolithiasis $\cdot$ Surgical repair
}

\begin{abstract}
Suture urolithiasis is an unusual but recognised phenomenon following surgery on the urinary tract. We report a case in a 30-year-old man who sustained a gunshot injury to the left ureter in Burundi and underwent open ureteric repair in a regional hospital. He migrated to the UK and presented one year later with left loin pain. An intravenous urogram revealed two foci of calcification to the left of $L 3$, within a peri-ureteric position. The patient underwent left-sided ureteroscopy where two calculi each formed around a nylon suture were discovered within a ureteric pseudo-diverticulum, and basketed. This is the first reported case of suture urolithiasis occurring following ureteric surgery.
\end{abstract}

Copyright $\odot 2015$ S. Karger AG, Basel

\section{Introduction}

Suture urolithiasis is an unusual but recognised phenomenon seen following open urological surgery and procedures closely related to the urinary tract. It most commonly occurs with the use of non-absorbable sutures [1]. While it has been reported as occurring within the bladder and renal pelvis [2, 3], we report an unusual case where suture calculi have formed within a pseudo-diverticulum following emergency ureteric surgery.

\section{KARGER}

Fax +4161306 1234

E-Mail karger@karger.ch

www.karger.com
(C) 2015 S. Karger AG, Basel

1015-9770/14/0091-0044\$38.00/0

Accessible online at:

www.karger.com/cur

\section{Case Report}

A 30-year-old gentleman presented with longstanding left loin pain radiating to the left leg. This followed a gunshot injury he sustained in his home African nation. He had emergency surgery there but due to on-going urinary leak had further surgical repair in another country on the same continent. Having moved to the UK as a political refugee he was then referred for urological opinion due to his left loin pain. On examination there was left renal angle tenderness. Urinalysis showed blood + . Blood tests demonstrated normal renal function, calcium and uric acid levels. An intravenous urogram was performed detecting 2 small foci of calcification to the left of the inferior border of the L3 vertebra on the control film (fig. 1). Post-contrast film demonstrated calyceal dilatation and clubbing in the left collecting system draining into a dilated left upper ureter to the level of L3. A narrower segment of ureter at the L3 to L4 level with 2 small radio-opacities by the side of the ureteric contrast suggested a peri-ureteric location (fig. 2). A MAG3 renogram showed a normal curve on the left side with no evidence of obstruction but the right kidney surprisingly contributing only $30 \%$ of total function. The patient underwent left ureteroscopy where two tiny calculi, each measuring less than $4 \mathrm{~mm}$ and formed around a non-absorbable suture, were discovered. These were seen lying free in a para-ureteric wide-mouthed pseudo-diverticulum, out of which they were easily popped and extracted individually using a basket (fig. 3). It was thought that this particular suture material had been used for the repair of the left ureter in Africa, but had then eroded into the left ureter, formed a pseudo-diverticulum and subsequently calculi. Stone analysis demonstrated oxalate composition. The patient made a good post-operative recovery and was subsequently discharged from further urology follow-up, although he re-presented 7 years later with bilateral loin pain, worse on the left. A CT urogram was performed suggesting a possible reformed small stone within the left ureteric pseudo-diverticulum, as well as a $2 \mathrm{~mm}$ right upper pole renal stone, but subsequent left retrograde pyelogram and 


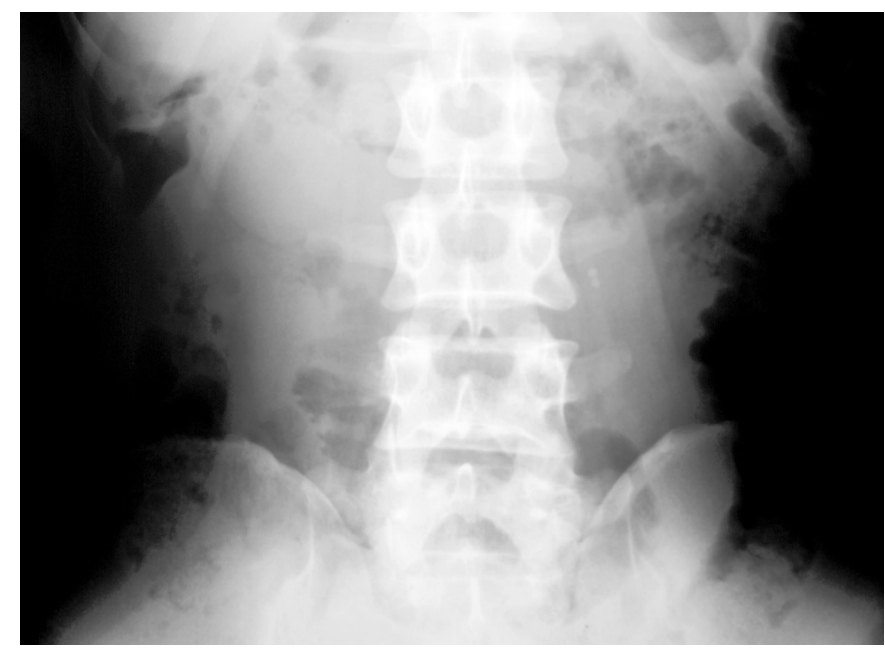

Fig. 1. Control film for intravenous urogram demonstrating two small foci of calcification to the left of the inferior border of the L3 vertebra.

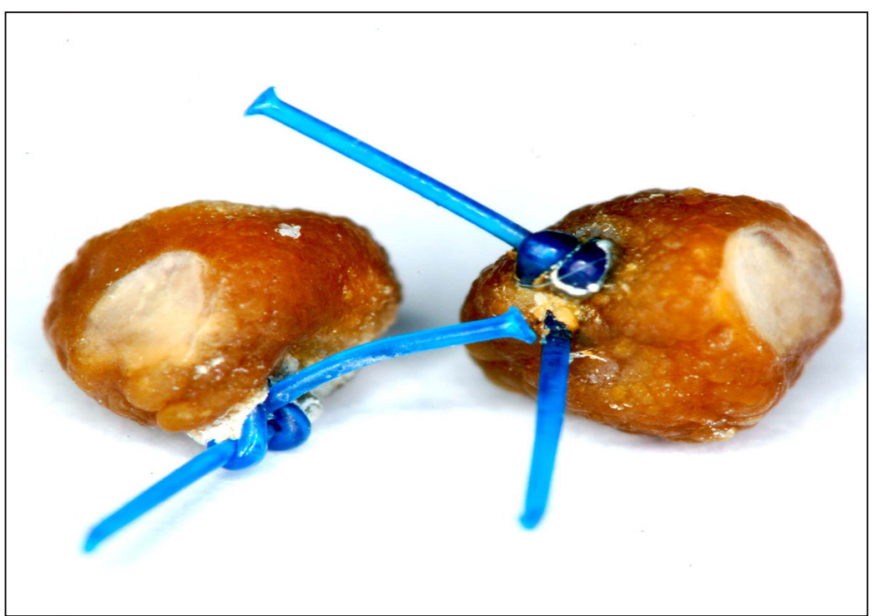

Fig. 3. The two calculi extracted from the left ureter, each formed around a non-absorbable suture.

ureteroscopy discovered no evidence of stones. Repeat MAG3 renogram demonstrated good drainage and equal function. The patient did not attend further appointments and so was discharged.

\section{Discussion}

Suture lithiasis has been reported more commonly in the urinary tract, both in animal subjects and case reports [1]. The most frequently reported urological location is the bladder following procedures such as diverticulec-

Ureteric Suture Lithiasis Following Open Ureteric Repair

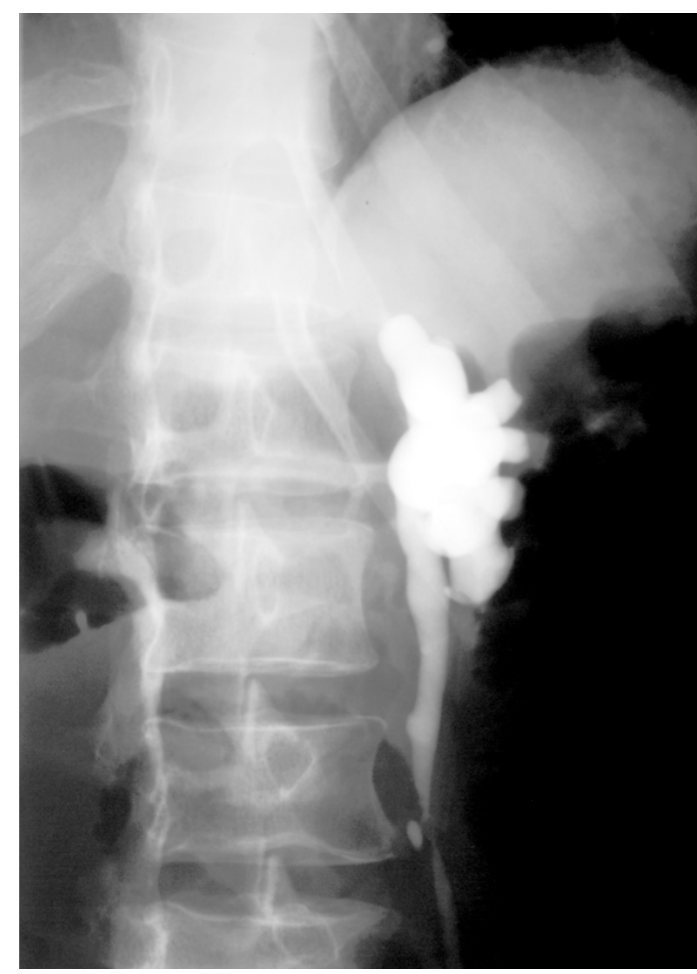

Fig. 2. Post-contrast film for intravenous urogram demonstrating calyceal dilatation and clubbing in the left collecting system, draining into a dilated left upper ureter to the level of L3; there is a narrower segment of ureter at the L3 to L4 level with two small radio-opacities by the side of the ureteric contrast, suggesting a peri-ureteric location.

tomy and colposuspension $[4,5]$. Extra-vesical operations have been involved, for example extrophy repair for pubic bone closure [6]. The most commonly implicated material is non-absorbable suture, likely due to prolonged contact time with urine thus acting as a nucleus around which crystallisation, calcification and eventually calculus formation. However there has been one case where a bladder stone had formed around absorbable suture after a radical prostatectomy [3].

There are very few reports within the medical literature of suture urolithiasis occurring within the upper urinary tract, specifically the renal pelvis; one occurred following urological surgery in the form of pyeloplasty and the other after subtotal colectomy [7, 8]. Suture material eroding through the wall of injured adjacent viscera to form stones has been described before, for example following hysterectomy to form a bladder stone [9]. There have however been no reports of suture calculi presenting for the first time having formed within the ureter. We therefore believe this to be the first case where suture 
urolithiasis has occurred specifically following open ureteric surgery, with the added uniqueness of such calculi having formed within a ureteric pseudo- diverticulum which itself had become established in relation to the same procedure.

This particular case raises other issues. Looking specifically at ureteric gunshot injury, most centres that have reported on their experience of managing this advocate the use of absorbable sutures for ureteric reconstruction [10]. This material however may not have been available at the time of our patient's surgery given his geographical location. In addition, given the relative ease today of international travel and migration it could be expected that such cases may be seen more frequently in the Western world. However, as outlined above suture urolithiasis has been demonstrated in patients living in developed nations and so an awareness of previous urological surgery should be applied to all patients regardless of country.

\section{Conclusion}

Suture urolithiasis can occur anywhere within the urinary tract following urological surgery, and procedures in close relation to the urinary tract, and most commonly where non-absorbable suture material has been used. Awareness of previous surgery and the types of material used are important when assessing such patients who present with subsequent stone disease within the urological tract.

\section{References}

1 Kosan M, Gonulalan U, Ozturk B, Kulacoglu $\mathrm{S}$, Erguder I, Akdemir OC, Cetinkaya M: Tissue reactions of suture materials (polyglactine 910 , chromed catgut and polydioxanone) on rat bladder wall and their role in bladder stone formation. Urol Res 2008;36:43-49.

2 Akin Y, Basara I: Urolithiasis on non-absorbable suture material: a rare case of bladder stone on polypropylene suture material. Singapore Med J 2011;52:851-852.

3 Cursio R, Choquenet C: Iatrogenic bladder stone formation on absorbable suture 3-years after radical prostatectomy. Minerva Urol Nefrol 2002;54:127-128.
4 Rafique M: Vesical calculus formation on permanent sutures. J Coll Physicians Surg Pak 2005;15:373-374.

5 Woo HH, Rosario DJ, Chapple CR: Stone formation on permanent suture material used previously in colposuspension. Br J Urol 1995;76:139-140.

6 Rub R, Madeb R, Morgenstern S, Ben-Chaim J, Avidor Y: Development of a large bladder calculus on sutures used for pubic bone closure following extrophy repair. World J Urol 2001;19:261-262.

7 Lock UC, von Pokrzywnitzki W, Weissbach L: Calculus formation after kidney pyeloplasty due to suture material. Urologe A 1998;37:522-525.
8 Lavallee LT, McCarthy JP, Norman RW: Suture urolithiasis in the renal pelvis secondary to prior subtotal colectomy. Can J Urol 2008 15:3928-3929.

9 Lu CM: Intravesical stone formation several years after hysterectomy: a case report. J Med Case Rep 2013;7:230.

10 Akay AF, Girgin S, Akay H, Sahin H, Bircan MK: Gunshot injuries of the ureter: one centre's 15-year experience. Acta Chir Belg 2006;106:572-577. 